\title{
ANALYSIS OF A POLLUTION TRANSMISSION PROCESS IN HEFEI CITY BASED ON MOBILE LIDAR
}

\author{
Shuai Zhang ${ }^{1, *}$, Zhaoming Zhou ${ }^{1}$, Conglei Ye ${ }^{1}$, Jibing Shi ${ }^{1}$, Peng Wang ${ }^{1}$, Dong Liu ${ }^{2}$ \\ ${ }^{1}$ Hefei GBo-Qua.Technology Co.,LTD, Hefei, Anhui 230088, China \\ ${ }^{2}$ Key Laboratory of Atmospheric optics, Anhui Institute of Optics and Fine Mechanics, Chinese Academy \\ of Sciences, Hefei, Anhui 230031, China \\ *Email: zhangshuai@gbqtech.com
}

\begin{abstract}
The air pollution has been regional in China with the development of economy. To monitoring the air pollution transmission, a new technique, mobile lidar system (GBQS01), was introduced. In this paper, a pollution transmission process happened on October $26^{\text {th }}, 2017$, was analyzed with the use of mobile lidar, air quality monitoring stations data, and Hysplit backward trajectories. The results showed that the polluted air mass was transferred from northeast under the force of air pressure. Under the influences of air pollution transmission and bad meteorological diffusion conditions, The $\mathrm{PM}_{10}$ quality concentrations in Hefei increased a lot within 5 hours; among all the 10 national air quality monitoring stations, the Luyang District (the northernmost one) and Changjiang Middle Road (the easternmost one) received the most serious impact with $\mathrm{PM}_{10}$ concentration reached up to $252 \mu \mathrm{g} / \mathrm{m}^{3}$ and $219 \mu \mathrm{g} / \mathrm{m}^{3}$ at 22:00 (Beijing Time).
\end{abstract}

\section{INTRODUCTION}

The air pollution in China has been extremely serious, with rapid development of economy but less concern of environment ${ }^{[1]}$. Atmospheric environment problem, as one of the hottest topics in scientific researches, has attracted attentions of the whole society recently. The main characteristic of air pollution in our country is the deterioration of air quality in urban areas, especially in large cities as Beijing, Shanghai and Guangzhou $^{[2]}$. Lidar, combining traditional radar technology with modern laser technology, is one of the most advanced active optical remote sensing instruments. It uses laser as light source, and remotely detects the targets by receiving the back-scattering signals produced by the interaction between laser and targets. Because of its high resolution, good direction, and small volume, it shows outstanding prospects in air quality monitoring and meteorological elements measurement ${ }^{[3]}$.

With further demand of environment monitoring, mobile lidar was manufactured by integrating the lidar into a motor vehicle. It inherits the advantages of fixed-point lidar in observation, and the mobility of vehicle at the same time, making the mobile monitoring of atmospheric environment come true.

A mobile lidar experiment was conducted in Hefei, combining with the data measured in the air quality monitoring stations and the backward trajectories retrieved by Hysplit model, to understand the trends of pollution transmission in October, 2017.

\section{METHODOLOGY}

\subsection{The mobile lidar system}

The mobile lidar system (GBQ-S01, Fig. 1), designed and manufactured by Hefei GBo-Qua Technology Co., LTD., having the utility of threedimensional observations of the atmospheric environment, was used in this project. This system integrates the aerosol lidar on a vehicle platform with a special data analysis software to present the real-time distribution of particle pollution, from near ground to over ten kilometers, along the navigation path.

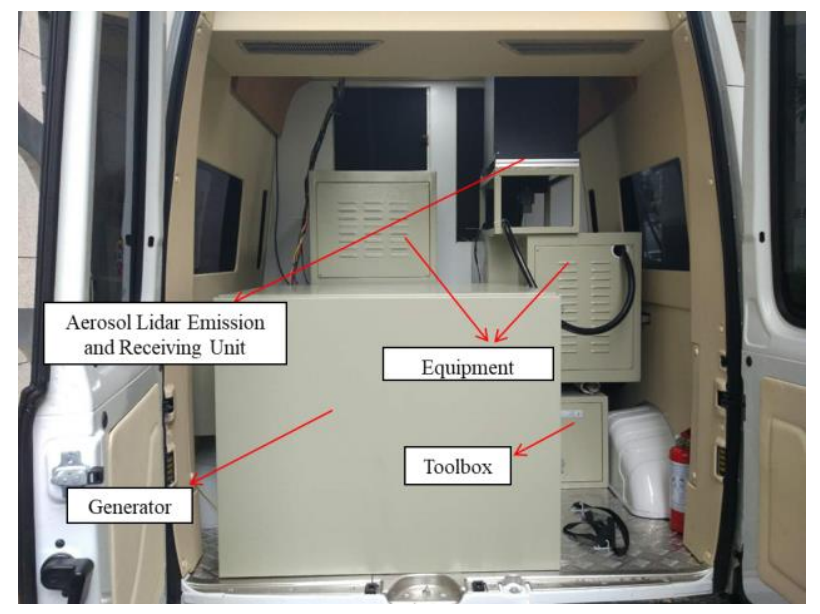

Fig. 1 Structure of mobile lidar system

\subsection{Aerosol lidar}


Aerosol lidar, the observation-device of mobile lidar system, contains two principal components: laser and telescope. The laser is used to emit pulsed laser light and the light will be expanded through a beam expander before it enters into atmosphere and reacts with molecules and aerosol particles. Some of the laser photon will be absorbed and also some of them will be scattered. The Cassegrain telescope is used to receive the backscattered signals and the signals will be filtered through a convergent lens before it enters into the signal acquisition channel. The polarization prism in the signal acquisition channel will polarize the received signals into vertical and parallel components, which will then be converted into electrical signals respectively by photodetectors in two designed channels. Extinction coefficient and depolarization ratio profiles, which indicate the vertical distribution of aerosol particles, can then be calculated from these electrical signals by using the Fernald method $^{[4-5]}$. The schematic diagram of aerosol lidar is shown in Fig. 2, and the main parameters of mobile lidar system are listed in Table 1.

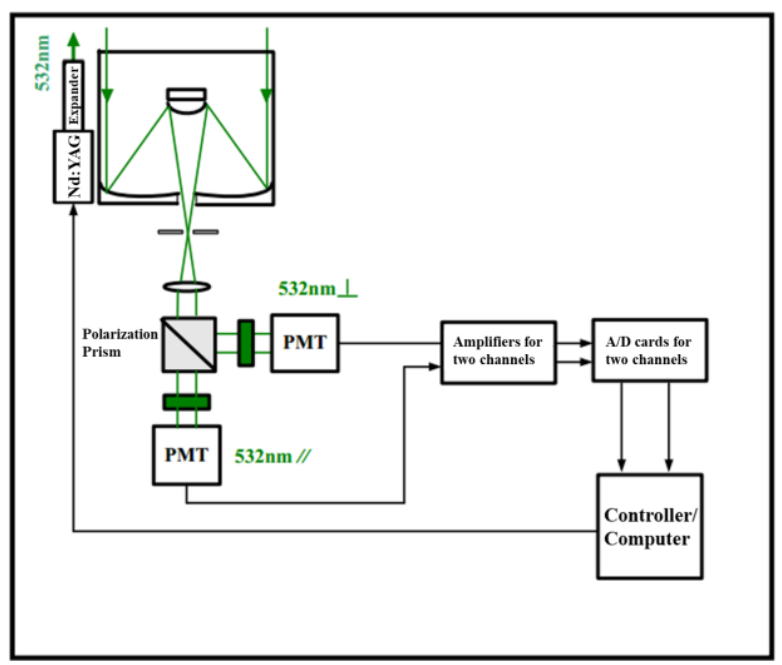

Fig. 2 Schematic diagram of aerosol lidar

Table 1 Main parameters of mobile lidar system

\begin{tabular}{ll}
\hline Parameters & Value \\
\hline Wavelength & $532 \mathrm{~nm}$ \\
Pulse energy & $>1 \mathrm{~mJ}$ \\
Repetition & $\geqslant 3 \mathrm{kHz}$ \\
Frequency &
\end{tabular}

Observation altitude $\geqslant 15 \mathrm{~km}$

Speed limits

$0-120 \mathrm{~km} / \mathrm{h}$

Temporal resolution $\quad 3 \mathrm{~s}-30 \mathrm{~min}$ (adjustable)

Spatial resolution $\quad 7.5 \mathrm{~m}$

\subsection{Data Acquisition}

\subsubsection{Mobile lidar experiment set up}

To track the pollution transmission channel of Hefei in a pollution process transmitted from northern areas, a mobile lidar observation experiment was designed and implemented on October $26^{\text {th }}, 2007$. The navigation routs are shown in Fig. 3.

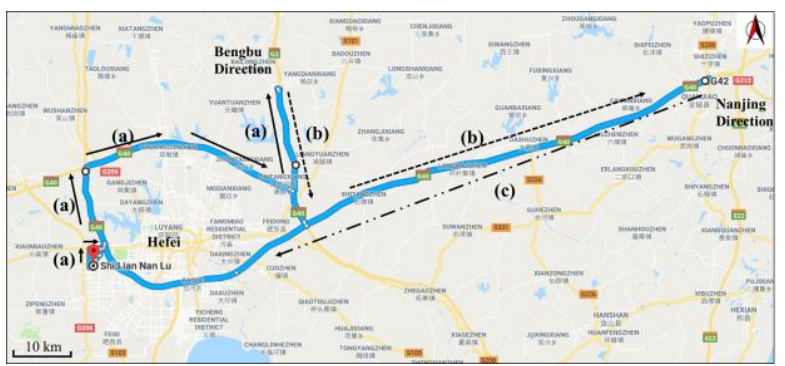

Fig. 3 Schematic chart of navigation path layered on google map

\subsubsection{Air quality data}

Air quality data are monitored, audited and released by the National Atmospheric Control Station. The detail introductions about the measuring instruments and methods are available in [6].

\subsubsection{Backward trajectories}

Three backward trajectories at different altitude $(500 \mathrm{~m}, 1000 \mathrm{~m}$ and $1500 \mathrm{~m})$ starting from Hefei were calculated by Hybird Single Particle Lagrangian Integrated Trajectory Model (HYSPLIT) $^{[7-8]}$.

\section{RESULTS}

\subsection{Mobile lidar observation results}

The mobile lidar observation results showed that aerosols in Hefei and its surrounding areas during navigation were mainly concentrated within 1.5 $\mathrm{km}$ altitude. At the northeast corner of Hefei, a pollution zone was detected at the altitude around $1.3 \mathrm{~km}$ as shown in Fig. 4(a) circled by a solid circle; and when we went northern (in the Bengbu 
direction), we also found a pollution zone at the same height as shown in Fig. 4(a) as dashed circle, but it disappeared on the way back (as shown in Fig. 4(b) as dashed circle). Meanwhile, the air was clear on the way to Nanjing and from Nanjing direction back to Hefei. In conclusion, the air pollution could transfer from the north-eastern direction under the force of air pressure.
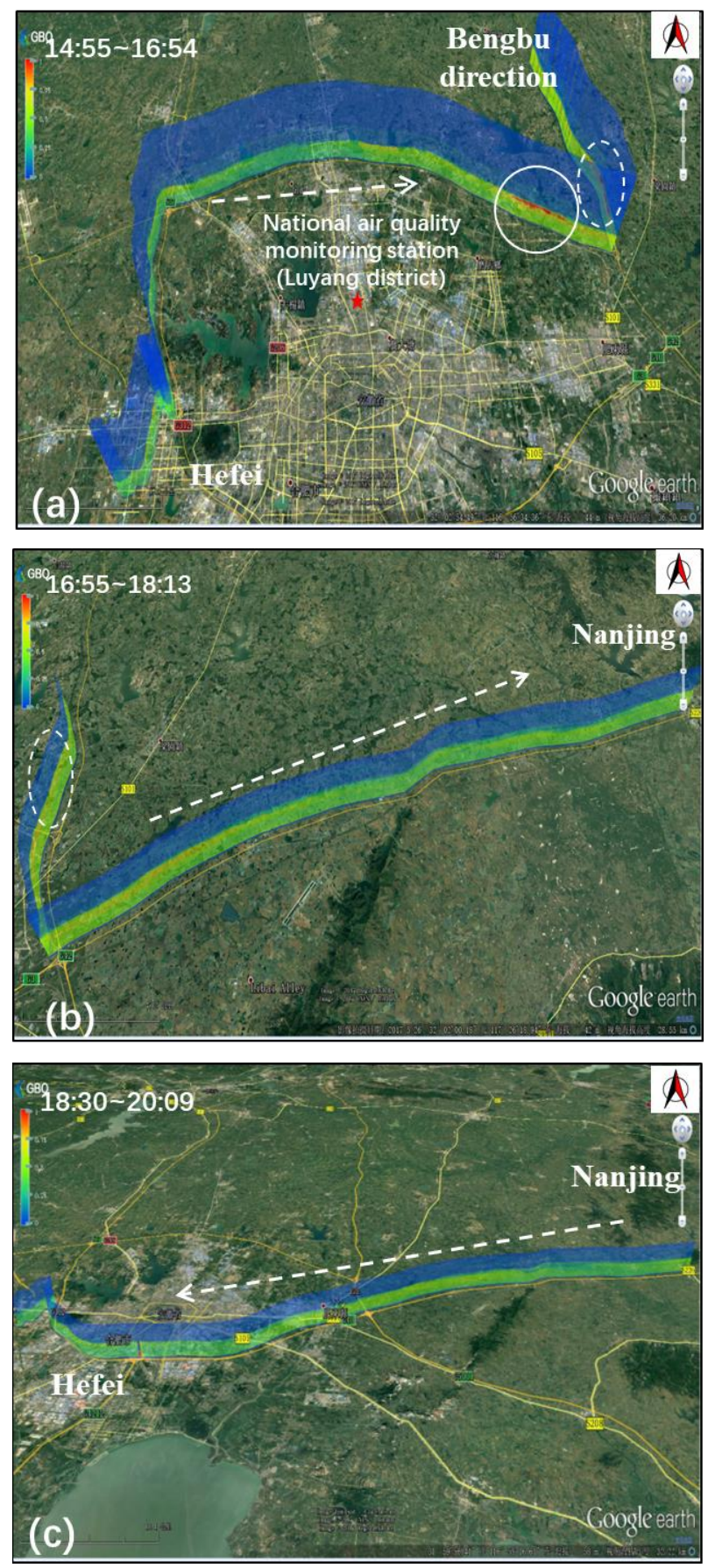

Fig. 4 Mobile lidar observation results

\subsection{Air quality data}

Measured $\mathrm{PM}_{10}$ quality concentrations, at 10 national air monitoring stations in Hefei, showed that Hefei was not affected in this reginal air pollution process until 17:00 (Beijing Time, BT). From 17:00 to 22:00 (BT), except for High-tech zone (the westernmost one) and Dongpu Reservoir (the northwesternmost one), the $\mathrm{PM}_{10}$ quality concentrations at other eight stations increased up to $100 \mu \mathrm{g} / \mathrm{m}^{3}$ or more. Among them, the Luyang District (the northernmost one) and Changjiang Middle Road (the easternmost one) received the most serious impact with $\mathrm{PM}_{10}$ concentration reached up to $252 \mu \mathrm{g} / \mathrm{m}^{3}$ and 219 $\mu \mathrm{g} / \mathrm{m}^{3}$ at 22:00 (BT). Thus, the same conclusion as mobile lidar observation can be gotten that the source of this regional air pollution is from the north-eastern direction.

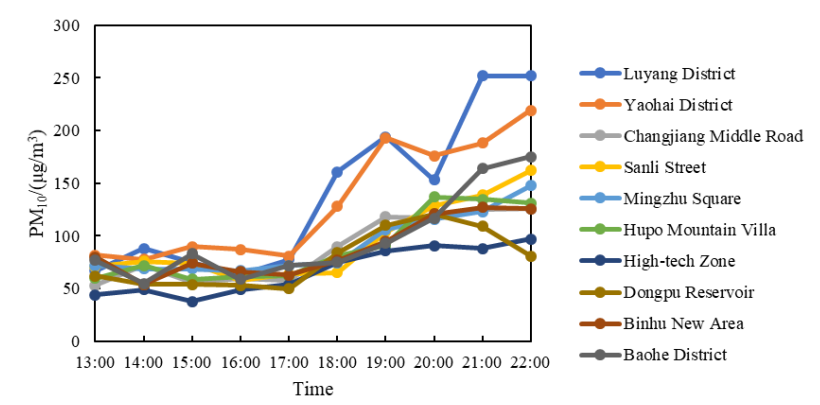

Fig. 5 Temporal variations of $\mathbf{P M}_{10}$ concentration measured at each air quality monitoring stations in Hefei on October $26^{\text {th }}$, 2017

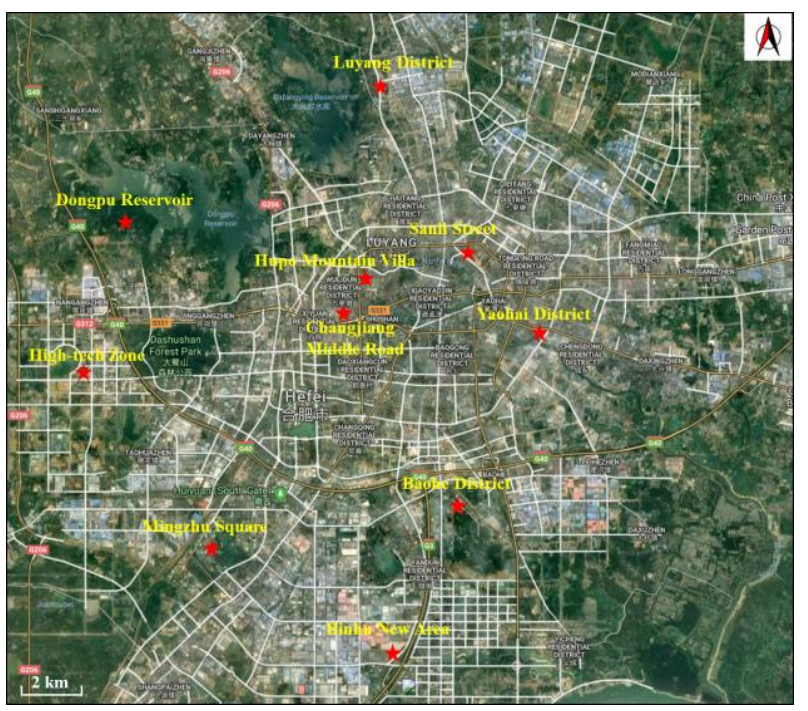


Fig. 6 Schematic map of the positions of air quality monitoring stations in Hefei layered on google map

\subsection{Backward trajectories}

The backward trajectories ending at 22:00 (BT) at lower altitude $(100 \mathrm{~m}$ and $500 \mathrm{~m})$ also showed that the air pollution in Hefei was from northeastern direction and the wind direction changed a lot in the last 24 hours. At higher altitude $(1000 \mathrm{~m})$, the air particles were transfer from northwest, that means the predominant wind direction at higher altitude was different from the ones at lower altitudes. Vertical wind shear was not good for the spread of polluted air mass that cased the serious pollution in Hefei.

NOAA HYSPLIT MODEL

Backward trajectories ending at 1400 UTC 26 Oct 17 GFSG Meteorological Data

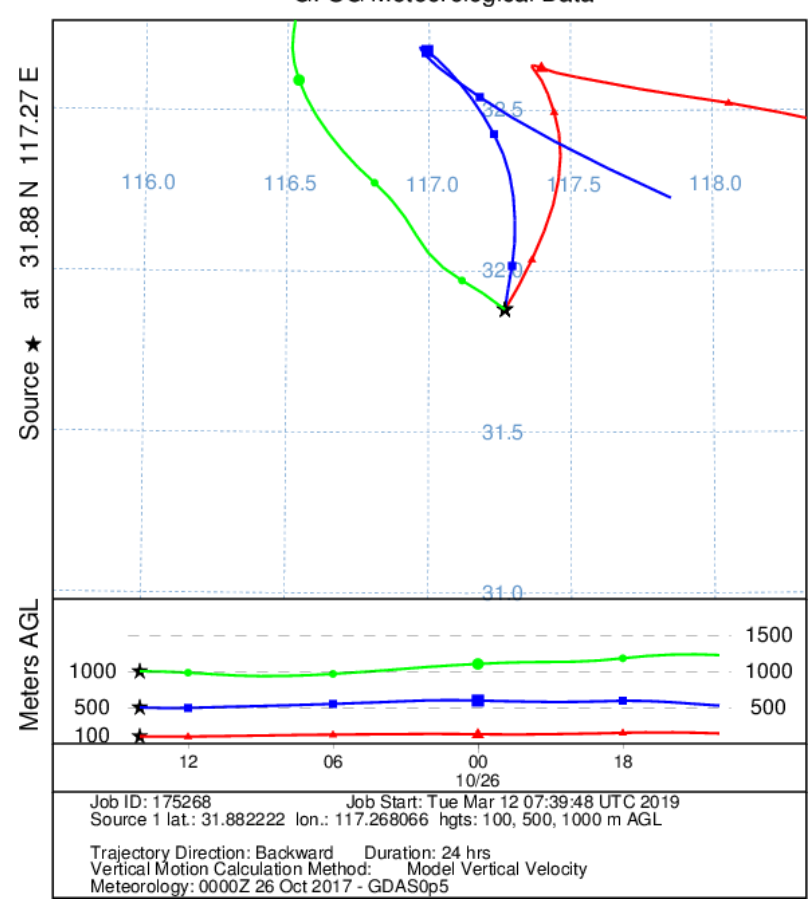

Fig. 7 Hysplit model simulated 24-hours

backward trajectories of Hefei ending at $22 \mathrm{pm}$

(Beijing Time) or 14 pm (Coordinated

Universal Time, UTC) on October 26th, 2017

\section{ACKNOWLEDGEMENTS}

The authors gratefully acknowledge the NOAA Air Resources Laboratory (ARL) for the provision of the HYSPLIT transport and dispersion model and/or READY website (http://www.ready.noaa.gov) used in this publication.

\section{REFERENCES}

[1] J. Hao, et al. Air pollution and its control in China. Frontiers of Environmental Science \& Engineering in China 1(2): 129-142 (2007).

[2] C. Chan, et al. Air pollution in mega cities in China. Atmospheric Environment 42(1): 1-42 (2008).

[3] Q. Yin, et al. Application of lidar in monitoring meteorological and atmospheric environment. Journal of Meteorology and Environment 25(5): 48-56 (2009).

[4] J. Shi, et al. Tropospheric aerosol measurements by lidar in Northern suburbs of Nanjing. Laser and Progress Optoelectronics, (10):73-81 (2012).

[5] F. G. Fernald. Analysis of atmospheric lidar observation: some comments. Appl. Opt., 23:652-653 (1984).

[6] X. Zhao, et al. Analysis on the spatial-temporal distribution characteristics of $\mathrm{O}_{3}$ and its influencing factors in Hefei City. Acta Scientiae Circumstantiae 38(2): 649-660 (2018).

[7] A. F. Stein, et al. NOAA's HYSPLIT atmospheric transport and dispersion modeling system. Bull. Amer. Meteor. Soc. 96, 2059-2077 (2015).

[8] G. Rolph, et al. Real-time Environmental Applications and Display system: READY. Environmental Modelling \& Software 95, 210-228 (2017). 